\title{
An experimental investigation on tool wear behaviour of uncoated and coated micro-tools in micro-milling of graphene-reinforced polymer nanocomposites
}

\author{
Niusha Shakoori ${ }^{1} \cdot$ Guoyu Fu $^{2} \cdot$ Bao Le ${ }^{1} \cdot$ Jibran Khaliq $^{1} \cdot$ Long Jiang $^{2} \cdot$ Dehong Huo $^{2} \cdot$ Islam Shyha ${ }^{1,3}$
}

Received: 3 October 2020 / Accepted: 27 January 2021 / Published online: 17 February 2021

(C) The Author(s) 2021

\begin{abstract}
Nanomaterials such as graphene have been added to various matrices to enhance mechanical, thermal and electrical properties for various applications requiring intricate designs at the micro-scale. At this scale, mechanical micro-machining is utilised as postprocessing to achieve high surface quality and dimensional accuracy while still maintaining high productivity. Therefore, in this study, the machinability of polymer nanocomposites in micro-scale (micro-machinability) is investigated. Graphene $(0.3 \mathrm{wt} \%)$ reinforced epoxy nanocomposites were fabricated using traditional solution mixing and moulding. The samples were then subjected to micro-milling at various cutting speeds using three different micro-tools, including uncoated, diamond and diamond-like carbon (DLC) tools. Mechanical and thermal properties of nanocomposite were also used to support the discussions. The result indicates that the DLC-coated tool shows better performance than the other tools for less tool wear, improved surface quality and less cutting forces.
\end{abstract}

Keywords Graphene $\cdot$ Polymer nanocomposites $\cdot$ Micro-milling $\cdot$ Micro-end mill $\cdot$ Diamond-like carbon $\cdot$ Tool wear $\cdot$ Tool Coating $\cdot$ Cutting force $\cdot$ Surface roughness

\section{Introduction}

In materials science, the term "nano" stands for a class of materials having at least one dimension in the range of 1$100 \mathrm{~nm}$ [1]. Various nanomaterials are currently investigated such as carbon nanotubes (CNTs), nano-clay and ceramic and metallic nanoparticles owing to their enhanced mechanical, thermal and electrical properties. Among these nanomaterials, graphene has been widely investigated in the past few decades as a reinforcing agent for polymers owing to its incredible mechanical [1], thermal [2] and electrical properties [3]

Bao Le

bao.le@northumbria.ac.uk

1 Department of Mechanical and Construction Engineering, Northumbria University at Newcastle, Newcastle upon Tyne NE1 8ST, UK

2 Mechanical Engineering, School of Engineering, Newcastle University, Newcastle upon Tyne NE1 7RU, UK

3 School of Engineering and the Built Environment, Edinburgh Napier University, Edinburgh EH10 5DT, UK compared to conventional reinforcements such as carbon fibre (CF) and graphite [4]. Graphene could also be used as electrodes in the electronics industry as stand-alone material. However, its most common applications are as a reinforcing material for polymer matrix in food packaging [5], aerospace [6], flame-retardant panel [7], coatings [8], automotive [9], wind turbine [10] and sports equipment's industries [11]. Graphene's high strength to weight ratio [12] could produce light-weight nanocomposite materials at low filler loading [13], which is a critical requirement in modern manufacturing [14]. Therefore, the applications of graphene-based polymer nanocomposites as structural materials have been growing at an incredible rate recently [15].

Even though the current manufacturing methods for composites (e.g. moulding and extrusion) can produce near-netshape nanocomposites, micro-machining is still required as a post-processing process to achieve high surface quality and dimensional accuracy [16]. Moreover, the need for manufacturing micro-parts or miniaturisation promptly increases in advanced industries [16]. Some micro-products, such as valves and mixing devices, micro-fluid systems, micro-nozzles for the high-temperature jet, fibre optics, micro-scale fuel cell and fluidic micro-chemical reactor with 
micro-scale pumps, are typical examples [17]. Figure 1 shows some micro-products as potential applications of micromachining of nanocomposites.

To fabricate micro-features with high accuracy, mechanical micro-machining techniques such as micro-turning, micro-drilling or micro-milling have been applied. These processes have shown their superior characteristics in generating complex 3D structures [20] and a wide range of workpiece material over other techniques such as photolithography [21]. However, nanocomposites' mechanical micro-machining has been considered a complicated process due to the effect of material's micro-structure (i.e. anisotropy, heterogeneity) thermo-mechanical properties associated with the inherent size effects of micromachining [16]. These factors lead to nanocomposites' poor machinability in terms of surface quality, cutting force variation and accelerated tool wear. Therefore, investigations on the micro-machining behaviours of nanocomposites are necessary. The increases of uncut chip thickness (UCT) [22] associated with cutting edge radius due to tool wear acceleration can result in cutting force rising in micro-machining of metals [23] or nanocomposites [16].

Additionally, the size effect exhibiting by the high specific cutting energy at small UCT results in high cutting force and surface roughness when micro-machining nanocomposites. It is also necessary to address the effects of thermo-mechanical properties of nanocomposite materials and their microstructures on the cutting mechanism (i.e. shearing, ploughing), the formation of built-up edge (BUE) and chip adhesion, hence subsequently influencing the machinability indicators. In general, surface roughness and cutting forces are two primary objectives in micro-machining nanocomposites studies.
Simultaneously, the investigations on tool wear behaviour have been still limited, especially in micro-machining of nanocomposites $[24,25]$. Therefore, the performances of different micro-tools (uncoated, DLC and diamond) when micromilling of graphene nanocomposites under dry cutting conditions are investigated in this paper. The machinability of graphene-reinforced epoxy nanocomposites is revealed via the analyses of cutting force, tool wear, surface roughness, surface integrity and dimensional accuracy.

\section{Experimental work}

\subsection{Nanocomposite fabrication}

Epoxy resin (polyfibre, Epophen TM EL5, density $\sim 1.3$ $\mathrm{g} / \mathrm{cm}^{3}$ ) is used as a matrix for making nanocomposites. Epoxy is degassed for $\sim 10 \mathrm{~min}$ in a vacuum chamber followed by addition of $0.3 \mathrm{wt} \%$ graphenes (Graphene, Laboratories Inc., USA) in epoxy resin using a bath sonicator (mixed for 30 min). Subsequently, the hardener is added and mixed using hand and bath sonicator for $5 \mathrm{~min}$ each. The mixture is then poured into silicone moulds having sample dimensions of $18 \times 13 \times 3 \mathrm{~mm}$. The mixture is cured for $24 \mathrm{~h}$ at room temperature followed by post-curing for $4 \mathrm{~h}$ at $80^{\circ} \mathrm{C}$.

\subsection{Micro-machining experiment}

Epoxy -0.3 wt $\%$ graphene nanocomposite is used throughout this research. Micro-end milling experiments are performed on a Desktop micro CNC machine (Nano-wave MTS5R) employing a maximum spindle speed of $80,000 \mathrm{rpm}$ and
Fig. 1 Potential applications of micro-machining of polymer nanocomposites. a SEM image of a micro-gear made from stainless steel/titania nanocomposites (copyright permission from [18]); b optical image of a micro-wheel; and $\mathbf{c}$ SEM image of a micro-gear made from epoxy/SiO2 nanocomposites (copyright permission from [19])
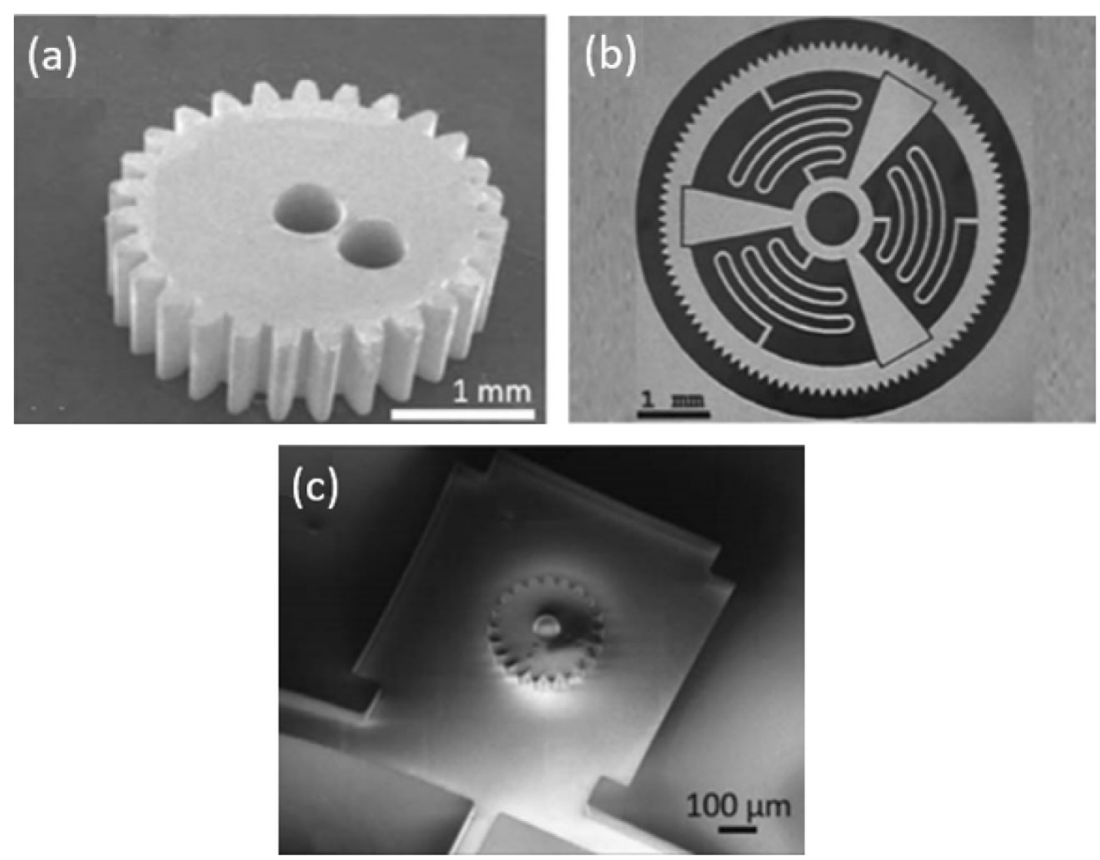
positioning accuracy of $\pm 1 \mu \mathrm{m}$ in each axis. Uncoated tungsten carbide end mills of 1-mm nominal diameter, 3-mm flute length and $30^{\circ}$ helix angle are tested against two coated end mills (diamond and DLC). Some characteristics of coating materials are shown in Table 1.

Dry cutting is applied throughout the experiments, and cutting length for each slot is kept at $13 \mathrm{~mm}$ (equal to the width of workpiece samples). Full immersion slot milling with a constant depth of cut (DoC) and feed rate of $100 \mu \mathrm{m}$ and $20 \mu \mathrm{m} / \mathrm{rev}$, respectively. Each slot's material removal volume is $1.3 \mathrm{~mm}^{3}(0.1 \mathrm{~mm} \times 1 \mathrm{~mm} \times 13 \mathrm{~mm})$. Figure 2 shows the experimental setup.

Kistler piezoelectric dynamometer $(9256 \mathrm{C} 2)$ is attached behind the fixture to measure cutting forces in $\mathrm{X}, \mathrm{Y}$ and $\mathrm{Z}$ direction. Fx and Fy are the two measured cutting force components along and perpendicular with feed direction, respectively, while Fz is axial to the cutting tool central line (Fig. 3). The generated signal from the dynamometer will be transferred to the charge amplifier (Kistler 5070A) then showed by Dynoware software for measuring cutting forces, using the formula below:

$$
\mathrm{F}=\sqrt{\mathrm{F}_{\mathrm{x}}^{2}+\mathrm{F}_{\mathrm{y}}^{2}+\mathrm{F}_{\mathrm{z}}^{2}}
$$

Tool diameters are measured using a TESCAN MIRA3 scanning electron microscope (SEM) and a Hitachi TM3030 table-top scanning electron microscope. Micro-graphs for tool wear and machined surface morphology are captured using the Hitachi TM3030 SEM. Average surface roughness (Ra) is measured at three different positions (entrance, middle and exit of each slot) on an Alicona Infinite Focus G4. Confirmation measurements are also performed on a Mitutoyo SJ-410 contact style profilometer. The Alicona microscope is also used to measure slot width to indicate such nanocomposite materials' dimensional accuracy. The details of experimental works including cutting parameters, tool and workpiece are summarised in Table 2.

\section{Results and discussion}

Experimental results of cutting forces, tool wear, workpiece surface integrity, surface roughness and slot width accuracy are discussed in this section.

Table 1 Tool coating characteristics

\begin{tabular}{llll}
\hline Coating material & Hardness & Friction coefficient & Ref. \\
\hline Diamond & $80-100 \mathrm{GPa}$ & $0.04-0.1$ & {$[26]$} \\
DLC & $2500(\mathrm{HV} \mathrm{0.05)}$ & $0.1-0.2$ & {$[27]$} \\
\hline
\end{tabular}
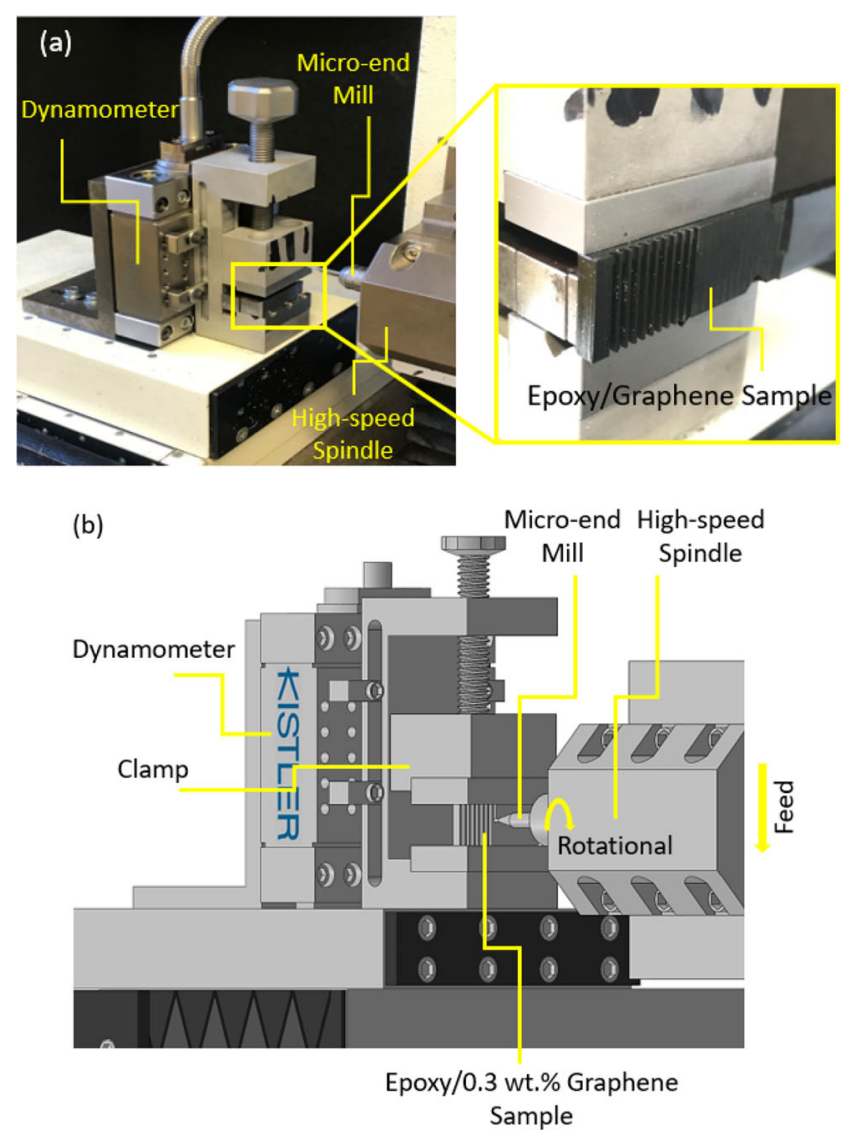

Fig. 2 a Experiment setup and $\mathbf{b}$ schematic represents the micro-end milling process

\subsection{Cutting force analysis}

In general, measured cutting forces are relatively higher at high cutting speed regardless of the tool type and the cutting stage (Fig. 4). These experimental results are different from the literature with the reductions of cutting forces as cutting speed increases when micro-milling PC/CNT [28] or epoxy/ graphene nanocomposites [24]. However, the mechanism that explains these variations is identically based on strengthening and thermal softening of the workpiece materials. Micromachining of nanocomposites at high cutting speed can generate high heat concentration in the cutting zone. Therefore, the rising trend of cutting forces from this study indicates the dominance of strengthening regime over thermal softening effects that can be validated by three factors: (i) the high mechanical properties of epoxy $/ 0.3 \mathrm{wt} \%$ nanocomposites including tensile strength, tensile modulus, fracture toughness and hardness, (ii) the uniform dispersion of graphene in the epoxy matrix that improves matrix-filler interfacial strength and (iii) the high thermal properties that minimise thermal softening effect or maintain mechanical stability of workpiece at such high cutting speed. As mentioned in the literature, graphene's addition into the epoxy matrix can improve mechanical properties and thermal properties that affect the machining 
Fig. 3 Cutting force measurement in micro-milling of graphene/epoxy nanocomposites

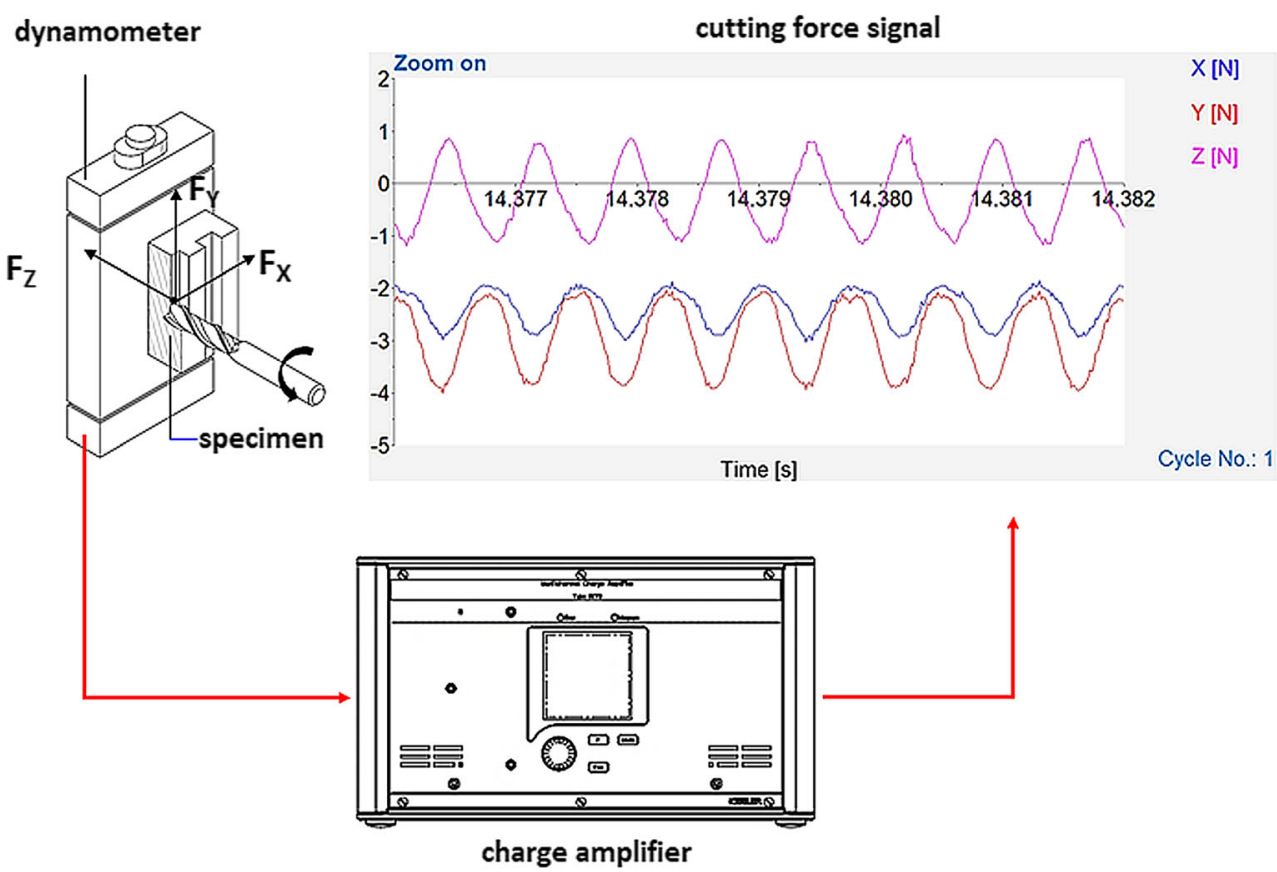

behaviours of these nanocomposites. Therefore, these properties need to be characterised to support for the micromachinability study.

Following epoxy/graphene nanocomposites' characterisations from the previous study [29, 30], the incorporation of $0.3 \mathrm{wt} \%$ of graphene into the epoxy matrix can provide optimal enhancements in terms of tensile strength, tensile modulus, fracture toughness and hardness. These improvements are due to the incorporation of graphene into the epoxy matrix in general. The high toughness and strength of

Table 2 Experimental settings

\begin{tabular}{|c|c|c|}
\hline \multirow[t]{3}{*}{ Specimen } & Material & $\begin{array}{l}\text { Graphene-reinforced } \\
\text { epoxy and plain } \\
\text { epoxy }\end{array}$ \\
\hline & $\begin{array}{l}\text { Dimension }(\mathrm{L} \times \mathrm{W} \times \mathrm{T}) \\
\quad(\mathrm{mm})\end{array}$ & $70 \times 13 \times 3$ \\
\hline & Filler loading (wt\%) & $0,0.3$ \\
\hline \multirow[t]{8}{*}{ Cutting tool } & Substrate material & $\begin{array}{l}\text { Micro-grain carbide } \\
\text { Co } 10 \%\end{array}$ \\
\hline & Grain size & $0.5-1 \mu \mathrm{m}$ \\
\hline & Number of flutes & 3 \\
\hline & Cutting diameter (mm) & 1 \\
\hline & Flute length (mm) & 4 \\
\hline & Helix angle & $30^{\circ}$ \\
\hline & Rake angle & $8-10^{\circ}$ \\
\hline & Coating materials & Diamond and DLC \\
\hline \multirow[t]{3}{*}{$\begin{array}{l}\text { Cutting } \\
\text { conditions }\end{array}$} & $\begin{array}{l}\text { Cutting speed }(\mathrm{m} / \mathrm{min}) \\
\quad(\mathrm{rpm})\end{array}$ & $\begin{array}{c}62.8(20,000) \text { and } \\
188.4(60,000)\end{array}$ \\
\hline & Feed rate $(\mu \mathrm{m} / \mathrm{rev})$ & 20 \\
\hline & Depth of cut (DoC) $(\mu \mathrm{m})$ & 100 \\
\hline
\end{tabular}

incorporated graphene lead to the improvements of nanocomposites' tensile properties. Moreover, graphene addition also increases the polymer nanocomposite's fracture toughness as graphene nanoplatelets enhance the energy-absorbing capacity of the epoxy matrix system. Simultaneously, these nanofillers' presence restrains the epoxy molecules' mobility, hence improving the hardness and the glass transition temperature Tg of the nanocomposites. However, graphene's reinforcing effect depends on the level of filler dispersion in the matrix that is mainly affected by the processing methods (Table 3) and the filler content (Table 4). In other words, the more uniform dispersion of graphene attained, the better the mechanical properties would be achieved. The uniform dispersion of $0.3 \mathrm{wt} \%$ graphenes in the epoxy matrix has been

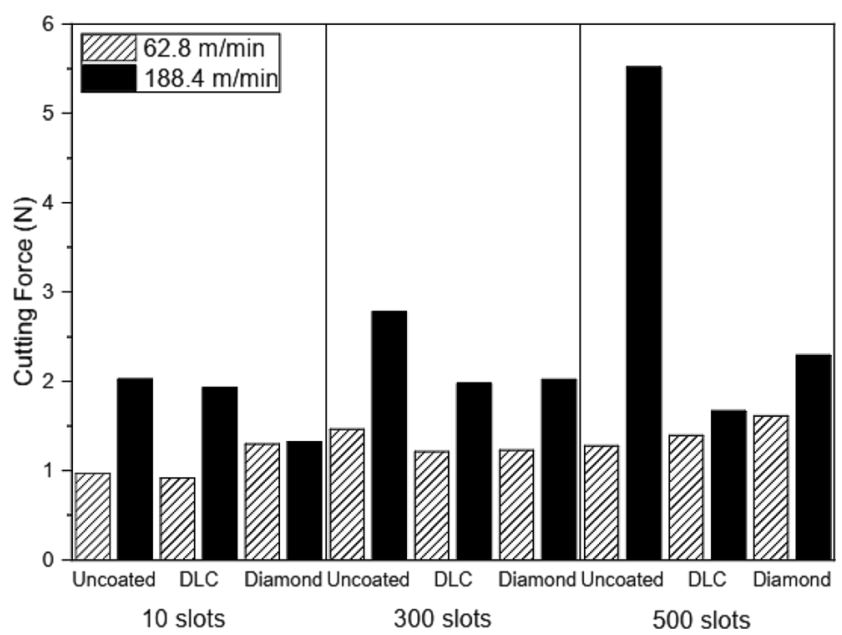

Fig. 4 Effects of cutting speed and tool coating type on the average cutting force at different cutting stages (from 10 to 500 slots) 
Table 3 Effect of the processing technique on mechanical properties of epoxy $/ 0.3 \mathrm{wt} \%$ graphene (compared with neat epoxy) (adapted from [29])

\begin{tabular}{lllll}
\hline $\begin{array}{l}\text { Processing } \\
\text { technique }\end{array}$ & $\begin{array}{l}\text { Tensile strength } \\
(\mathrm{MPa})\end{array}$ & $\begin{array}{l}\text { Tensile modulus } \\
(\mathrm{GPa})\end{array}$ & $\begin{array}{l}\text { Fracture toughness } \\
\left(\mathrm{MPa} . \mathrm{m}^{1 / 2}\right)\end{array}$ & $\begin{array}{l}\text { Hardness } \\
(\mathrm{GPa})\end{array}$ \\
\hline Hand mixing & $57.3(0.4 \%)$ & $0.92(6 \%)$ & $0.71(3.7 \%)$ & $0.224(3.7 \%)$ \\
Tip sonication & $59.1(3.4 \%)$ & $0.96(10 \%)$ & $0.77(12.8 \%)$ & $0.227(5.2 \%)$ \\
Bath sonication & $64.4(12.7 \%)$ & $1.17(34.3 \%)$ & $0.83(20.8 \%)$ & $0.235(8.8 \%)$ \\
\hline
\end{tabular}

Table 4 Effect of filler content on mechanical properties of epoxy/graphene nanocomposites (compared with neat epoxy) (adapted from [29, 30])

\begin{tabular}{|c|c|c|c|c|c|}
\hline Content (wt\%) & Tensile strength (MPa) & $\begin{array}{l}\text { Tensile modulus } \\
\text { (GPa) }\end{array}$ & $\begin{array}{l}\text { Fracture toughness } \\
\left(\mathrm{MPa} \cdot \mathrm{m}^{1 / 2}\right)\end{array}$ & Hardness (GPa) & $\begin{array}{l}\text { Glass transition } \\
\text { temperature }\left({ }^{\circ} \mathrm{C}\right)\end{array}$ \\
\hline 0.1 & $60.51(5.7 \%)$ & $1.030(18.7 \%)$ & $0.761(10.8 \%)$ & $0.225(4.3 \%)$ & $97.15(4.0 \%)$ \\
\hline 0.3 & $64.44(12.6 \%)$ & $1.169(13.5 \%)$ & $0.831(21 \%)$ & $0.235(8.8 \%)$ & $99.08(6.1 \%)$ \\
\hline 0.5 & $63.84(11.5 \%)$ & $1.219(4.3 \%)$ & $0.805(17.2 \%)$ & $0.246(13.9 \%)$ & $98.35(5.3 \%)$ \\
\hline 1 & $58.53(2.3 \%)$ & $1.360(11.5 \%)$ & $0.734(6.8 \%)$ & $0.255(18.1 \%)$ & $97.12(40 \%)$ \\
\hline
\end{tabular}

characterised using SEM imaging for the fractured surfaces. The SEM images revealed the highly uniform dispersion of graphene using bath sonication. Simultaneously, some uneven distributions of these nano-fillers could be seen on the fracture surfaces in hand mixing and tip sonication. The addition of $0.3 \mathrm{wt} \%$ of graphene using bath sonication also showed the highest filler distribution level over the other filler contents $(0.1 \mathrm{wt} \%, 0.5 \mathrm{wt} \%$ and $1.0 \mathrm{wt} \%)$.

The high mechanical properties of $0.3 \mathrm{wt} \%$ graphene/ epoxy nanocomposites (Table 3 and Table 4) contribute to the rising trend of cutting force at cutting speed from 62.8 $\mathrm{m} / \mathrm{min}$ to $188.4 \mathrm{~m} / \mathrm{min}$. Figure 4 also shows the higher cutting force when using uncoated micro-tools at high cutting speed over other two tool types. This trend becomes more evident as cutting volume increases and reaches a peak at the end of the cutting process (500 slots). These results are similar to other studies when micro-milling aluminium [31]. Micro-milling polymer nanocomposites, using uncoated tools with high friction coefficient, can accelerate the tool wear rate, leading to cutting edge roundness, hence increasing the cutting force. This hypothesis needs to be validated by the tool wear analysis using SEM imaging in the next section.

\subsection{Tool wear analysis}

Figure 5a shows SEM image of a typical tool diameter reduction of the uncoated tool, while Fig. 5b shows a comparison between three tools diameters (uncoated, DLC and diamond) after cutting 500 slots (at two different cutting speeds). The initial diameters of the three tools are different because of the coating layer. In general, uncoated micro-end mill shows the most considerable reduction of tool diameter following by DLC counterpart. In contrast, the diamond tool exhibits the opposite trend with a slight increase in this category.
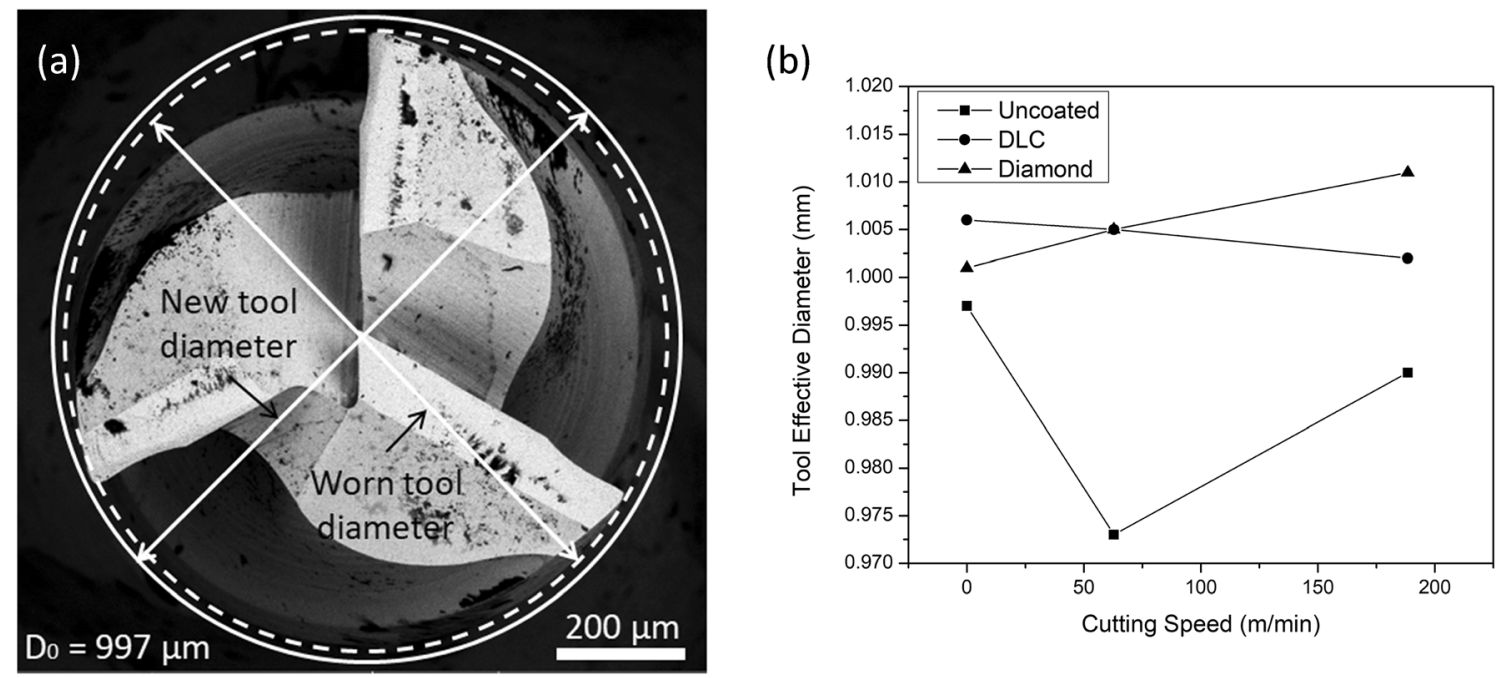

Fig. 5 a SEM image of tool diameter reduction of the uncoated tool. b Effect of tool type and cutting speed on reducing the effective tool diameter 
The rapid tool wear of uncoated tools is contributed by the high abrasive of strong workpiece material (Table 3 and Table 4) combined with the tool material's high friction coefficient. The SEM images from Fig. $6 \mathrm{a}$ and $\mathrm{d}$ with noticeable edge rounding of the uncoated, regardless of the cutting speed, are revealed. However, the uncoated tool diameter variation is different from the other two tool types with a non-linear trend. Unexpectedly, the uncoated tool diameter increases when cutting speed reaches $188.4 \mathrm{~m} / \mathrm{min}$ instead of being further reduced. In a close investigation, Fig. $6 \mathrm{~d}$ shows more obvious chip adhesion on the uncoated tool surfaces at the high cutting speed than unlikely to appear at the lower cutting speed (Fig. 6a).

However, the apparent uncoated tool tip rounding can also be seen in Fig. 7d, contributing to this cutting condition's highest cutting force (Fig. 4). The mechanism that explains the tool radius's effect on cutting force in micro-machining has been described [16]. It details that (i) the increase of tool
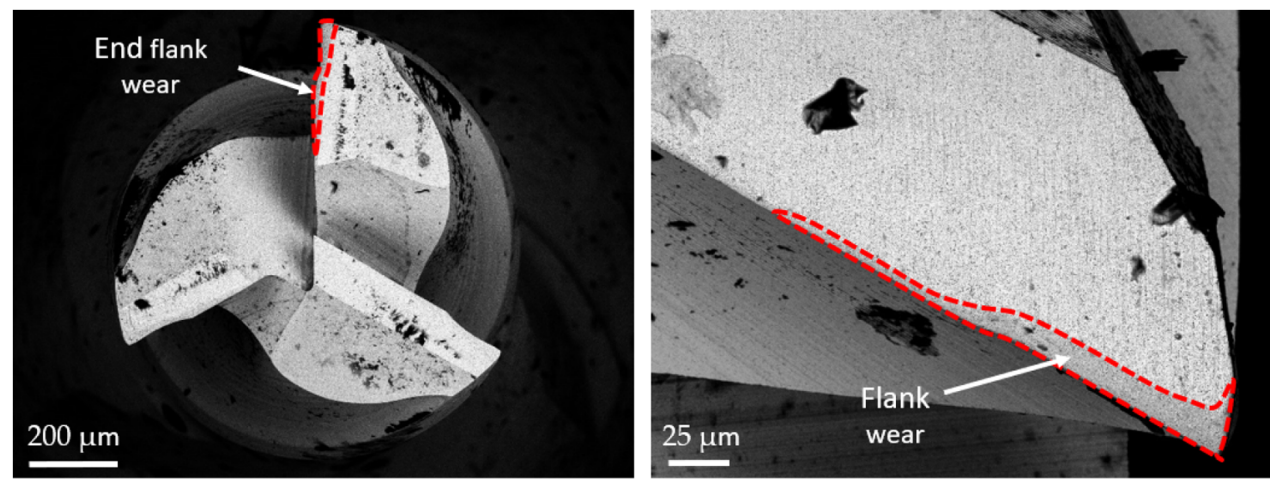

(a)
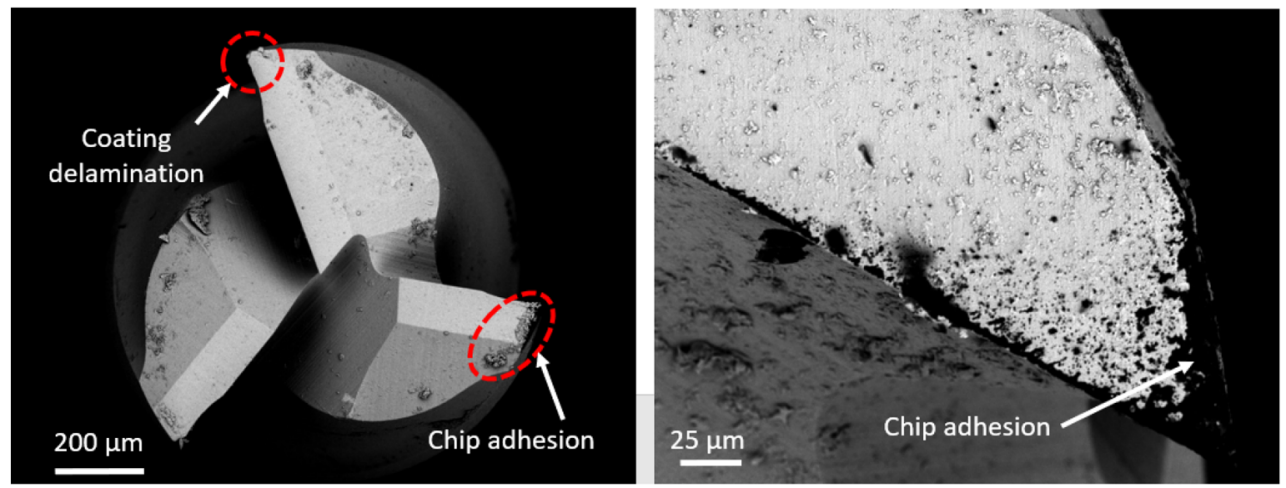

(b)
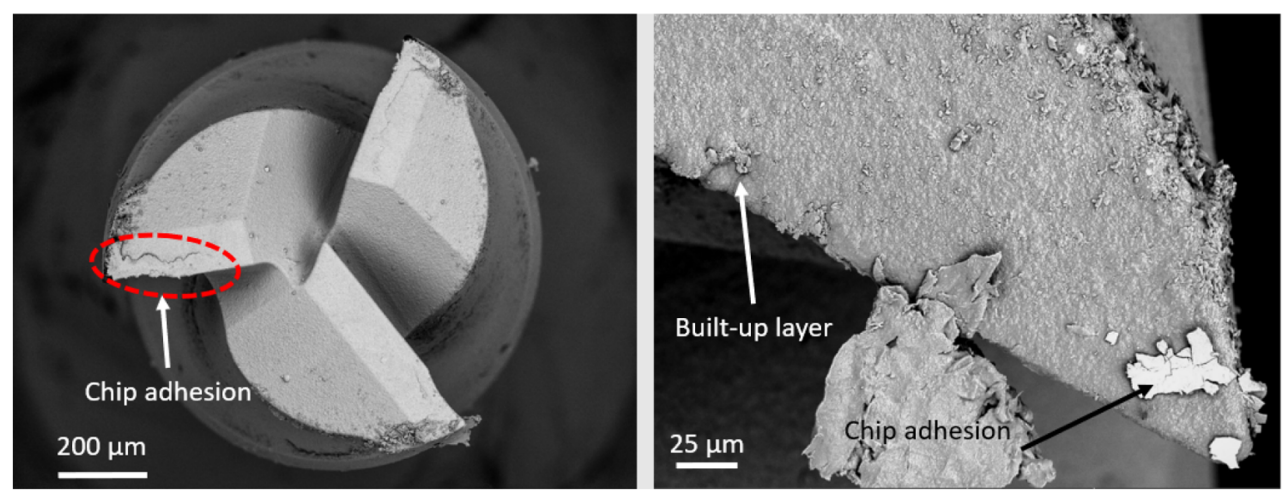

(c)

Fig. 6 SEM images of tool wear of different micro-end mills under various cutting speed (after removing $650 \mathrm{~mm}^{3}$ of material or 500 slots) (left: top view, right: side view). a Uncoated tool at cutting speed of 62.8 $\mathrm{m} / \mathrm{min}$. b DLC tool at cutting speed of $62.8 \mathrm{~m} / \mathrm{min}$. c Diamond tool at cutting speed of $62.8 \mathrm{~m} / \mathrm{min}$. d Uncoated tool at cutting speed of 188.4 $\mathrm{m} / \mathrm{min}$. e DLC tool at cutting speed of $188.4 \mathrm{~m} / \mathrm{min}$. f Diamond tool at cutting speed of $188.4 \mathrm{~m} / \mathrm{min}$ 

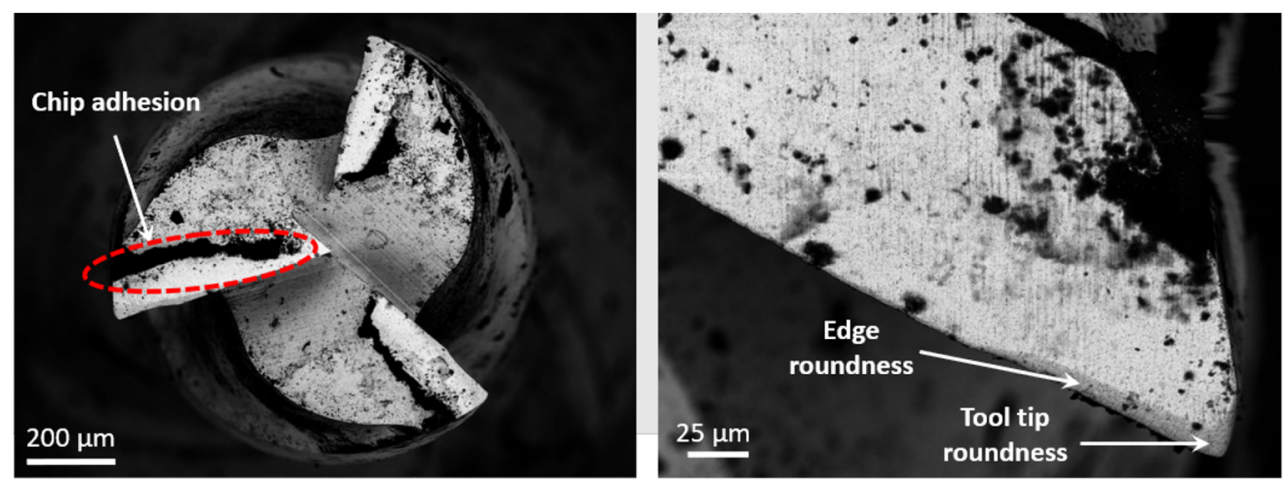

(d)
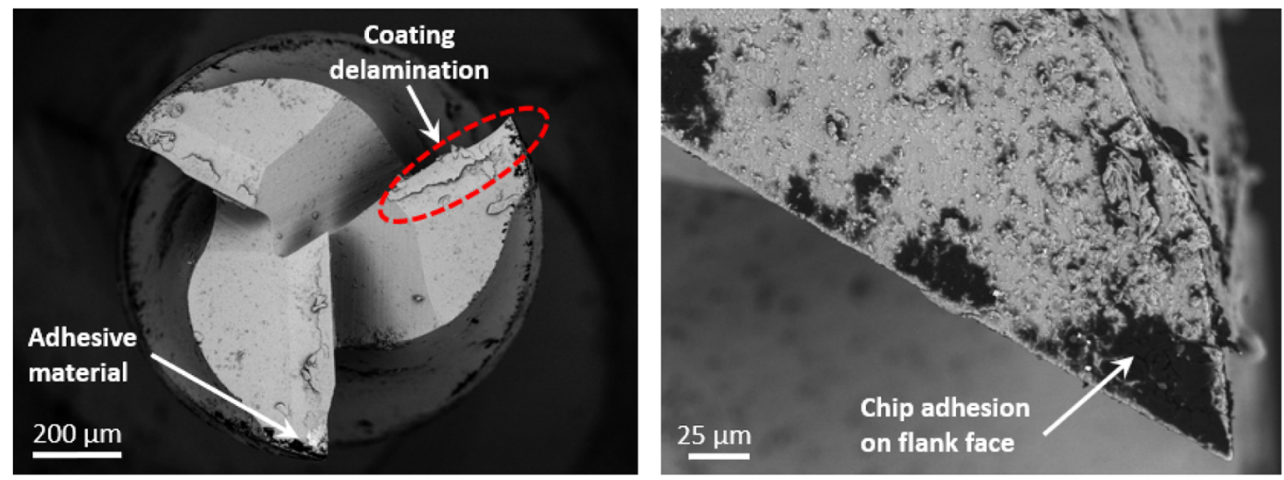

(e)
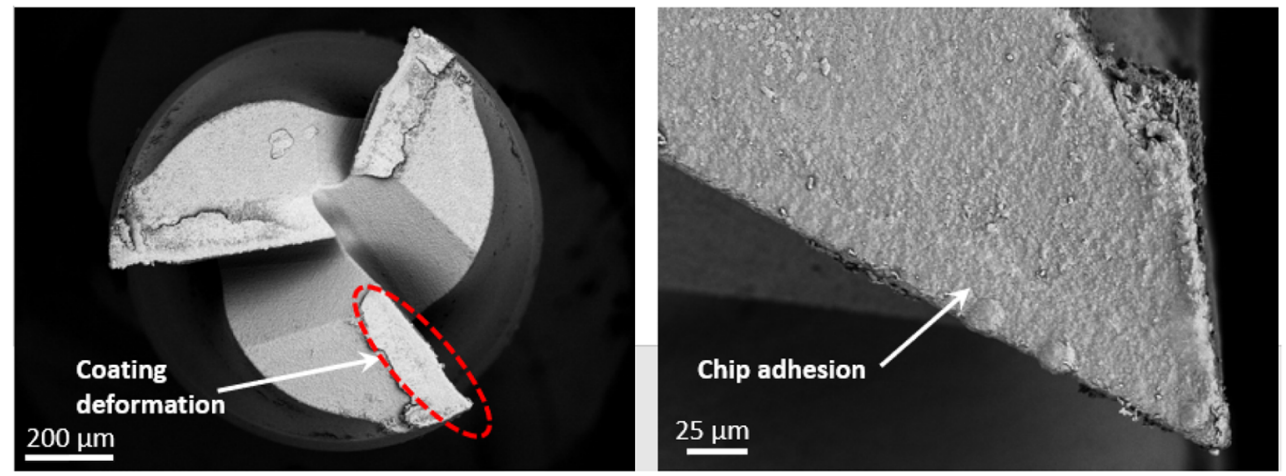

(f)

Fig. 6 continued.

radius due to tooltip roundness makes the micro-tools blunt, consequently, generating high shear angle in cutting area or high plastic deformation of the workpiece, hence increasing cutting force, and (ii) the tooltip roundness increases the contact area between flank face and workpiece, therefore, accelerating flank wear rate. It generates high cutting temperature [23], especially when micro-cutting inhomogenous nanocomposites using uncoated tools with the high friction coefficient at high cutting speed. Thus, the thermal softening effect seems dominant in this case, causing more chip adhesion on the flank face of the uncoated tool (Fig. 6d), hence increasing the tool diameter at the cutting speed of $188.4 \mathrm{~m} / \mathrm{min}$.
In the DLC case, the tool diameter reduction trend shows linear relation with cutting speed that indicates the dominance of cutting force influence on accelerating the tool wear of this type of micro-cutting tools. However, this trend is less severe than those of the uncoated tool. It is due to the high wear resistance and low friction of DLC coating layer [32]. The use of DLC micro-end mill has shown the remarkable reduction of flank wear [33]. This reduction can be seen from Fig. $6 \mathrm{~b}$, e with unobvious tool flank wear or less tool tip rounding from Fig. 7b, e compared to those of uncoated tool. Coating delamination seems to be the primary tool to wear pattern in this case. The tool flank surfaces also show material adhesion 

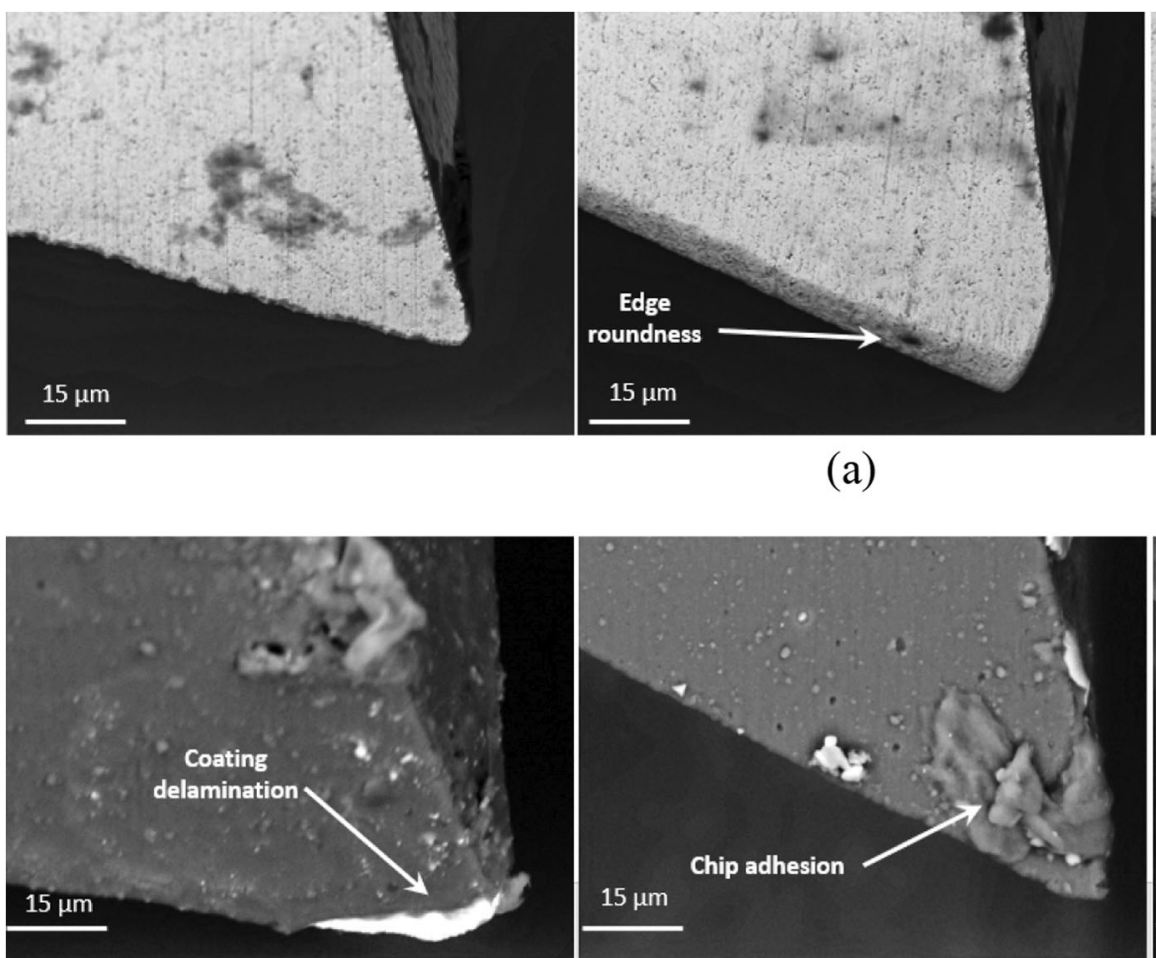

(b)
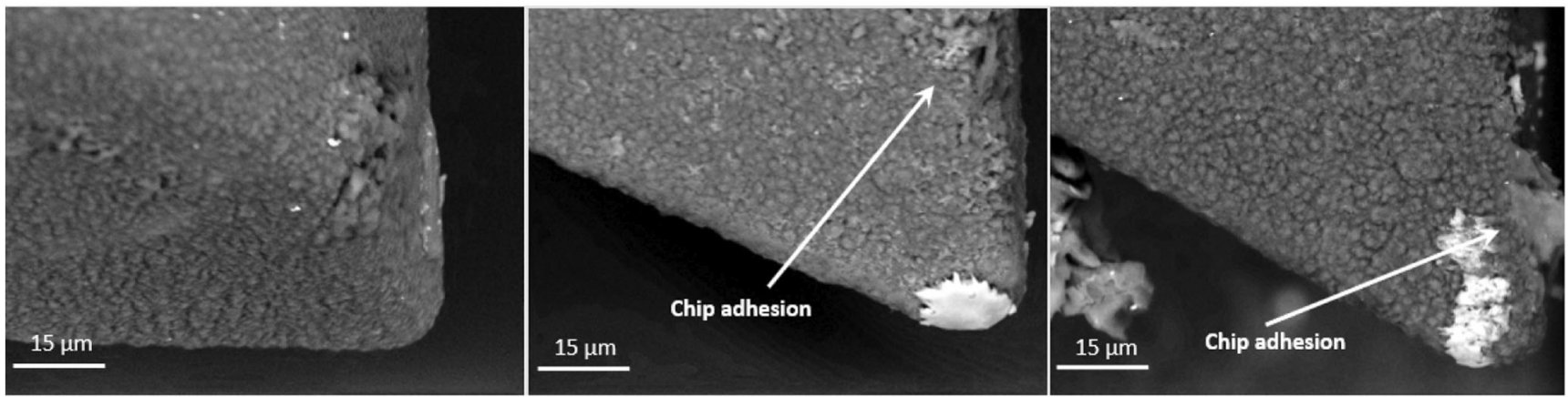

(c)

Fig. 7 SEM images showing tool wear progression of different microend mills under the various cutting speed (From left to right: 10 slots, 300 slots and 500 slots). a Uncoated tool at cutting speed of $62.8 \mathrm{~m} / \mathrm{min}$. b DLC tool at cutting speed of $62.8 \mathrm{~m} / \mathrm{min}$. $\mathbf{c}$ Diamond tool at cutting speed

that may also contribute to a slighter reduction in a DLC tool's diameter than an uncoated tool.

On the contrary, an opposite trend of the tool diameter after cutting 500 slots is reported when applying diamond tool with an increase in diameter of $10 \mu \mathrm{m}$ (at $188.4 \mathrm{~m} / \mathrm{min}$ ) and $4 \mu \mathrm{m}$ (at $62.8 \mathrm{~m} / \mathrm{min}$ ) compared to the new tool. Edge rounding is hardly observed for diamond tools (Fig. 6c, f). Moreover, aggressive workpiece material adhesions are seen on all diamond tools used at both cutting speeds. The layers of chip adhesion on tool surfaces can protect cutting tools from edge chipping and severe edge rounding [25]. It is also necessary to of $62.8 \mathrm{~m} / \mathrm{min}$. d Uncoated tool at cutting speed of $188.4 \mathrm{~m} / \mathrm{min}$. e DLC tool at cutting speed of $188.4 \mathrm{~m} / \mathrm{min}$. f Diamond tool at cutting speed of $188.4 \mathrm{~m} / \mathrm{min}$

address low cutting forces' role when using diamond tools to reduce the tool wear compared to those of uncoated tools (Section 3.1).

The analysis of tool wear reveals the interaction between tool wear and cutting force. Micro-machining polymer composites with high mechanical properties (i.e. fracture toughness, hardness) and thermal properties (i.e. thermal conductivity) at high cutting speed can lead to higher tool wear rate. At high tool wear rate, the micro-tools become blunt, hence increase the cutting force. This interaction is shown in micromilling using the uncoated tool in this study, exhibiting severe 

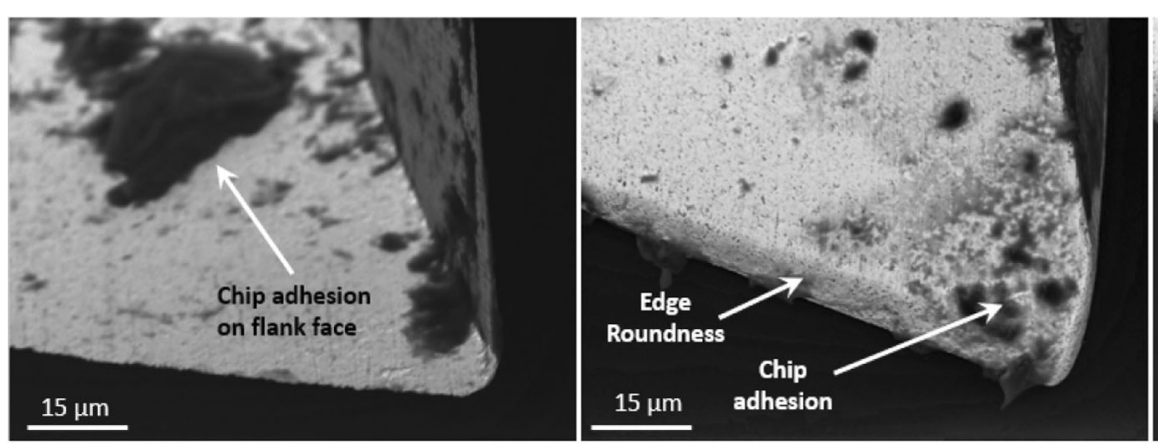

(d)
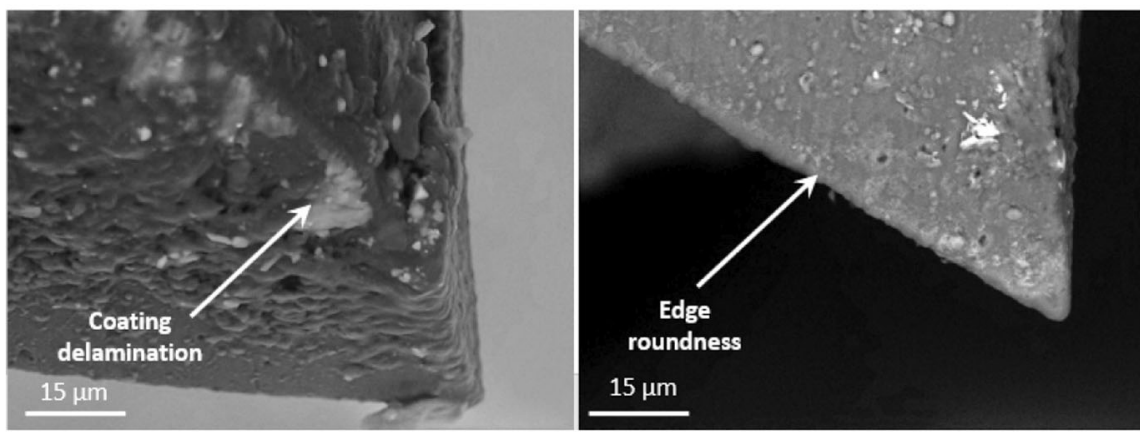

(e)
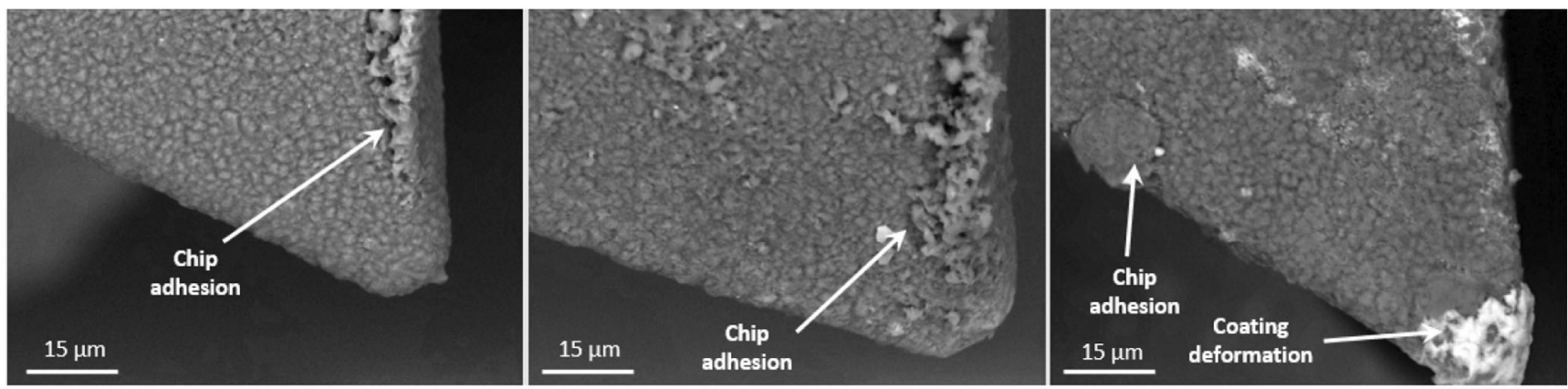

(f)
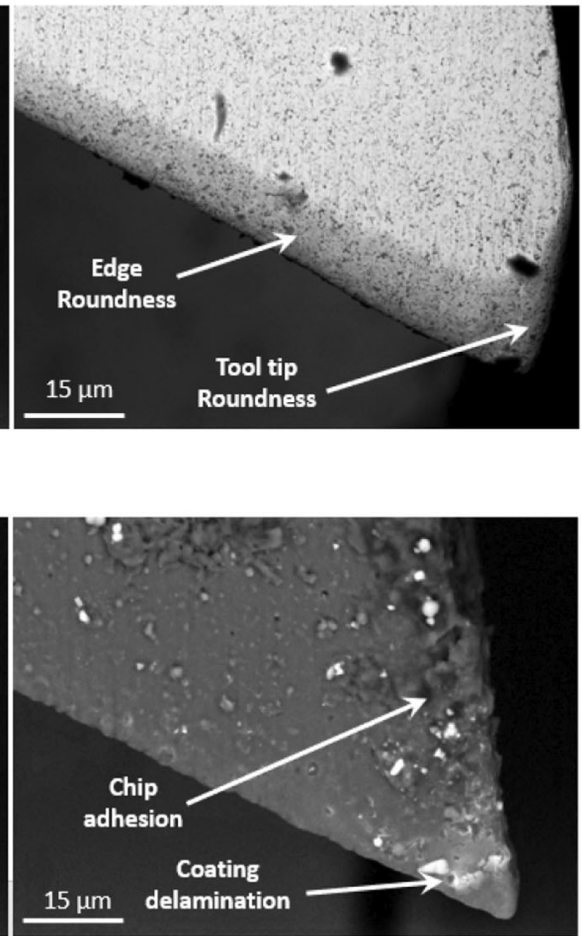

$15 \mu \mathrm{m}$

Fig. 7 continued.

tool wear progress (Fig. 7) and high cutting force at high cutting speed (Fig. 5b). It also highlights the essential roles of coating material such as DLC or diamond to reduce both cutting force and tool wear during the micro-cutting process.

\subsection{Surface roughness analysis}

Average surface roughness (Ra) is measured at an interval of 100 slots for a set of conditions till 500 slots $\left(650 \mathrm{~mm}^{3}\right)$. It would also be necessary to identify Ra when new tools are used (up to 10 slots or $13 \mathrm{~mm}^{3}$ ). Figure 8 shows the progress of Ra values concerning tool wear (represented in terms of material removal volume). The Ra magnitudes of coated tools (DLC and diamond) at the beginning of the cutting processes (up to $13 \mathrm{~mm}^{3}$ removed material) are higher than those of uncoated counterpart. The thickness of coating layers might reduce these coated tools' sharpness, consequently increasing surface roughness [34]. Only uncoated tools exhibited a gradual rise in Ra, especially for high cutting speed $(188.4 \mathrm{~m} / \mathrm{min})$.

In contrast, diamond and DLC-coated tools mostly showed constant Ra values of $650 \mathrm{~mm}^{3}$ removed material. The considerable reduction in sharpness of cutting edges for the uncoated tools due to its higher tool wear rate than those of the coated tools (DLC and diamond) is the main reason for this phenomenon. The surface roughness results show a good agreement with the tool wear analysis (Fig. 7).

Considering the effect of cutting speed on Ra, the surface roughness magnitudes of uncoated tool tend to be higher when high cutting speed is employed. Following the analysis in Section 3.1 (Fig. 4), the cutting force is always higher at high cutting speed, indicating the effect of rising cutting forces on the deterioration of the surface quality as the coated tool is 

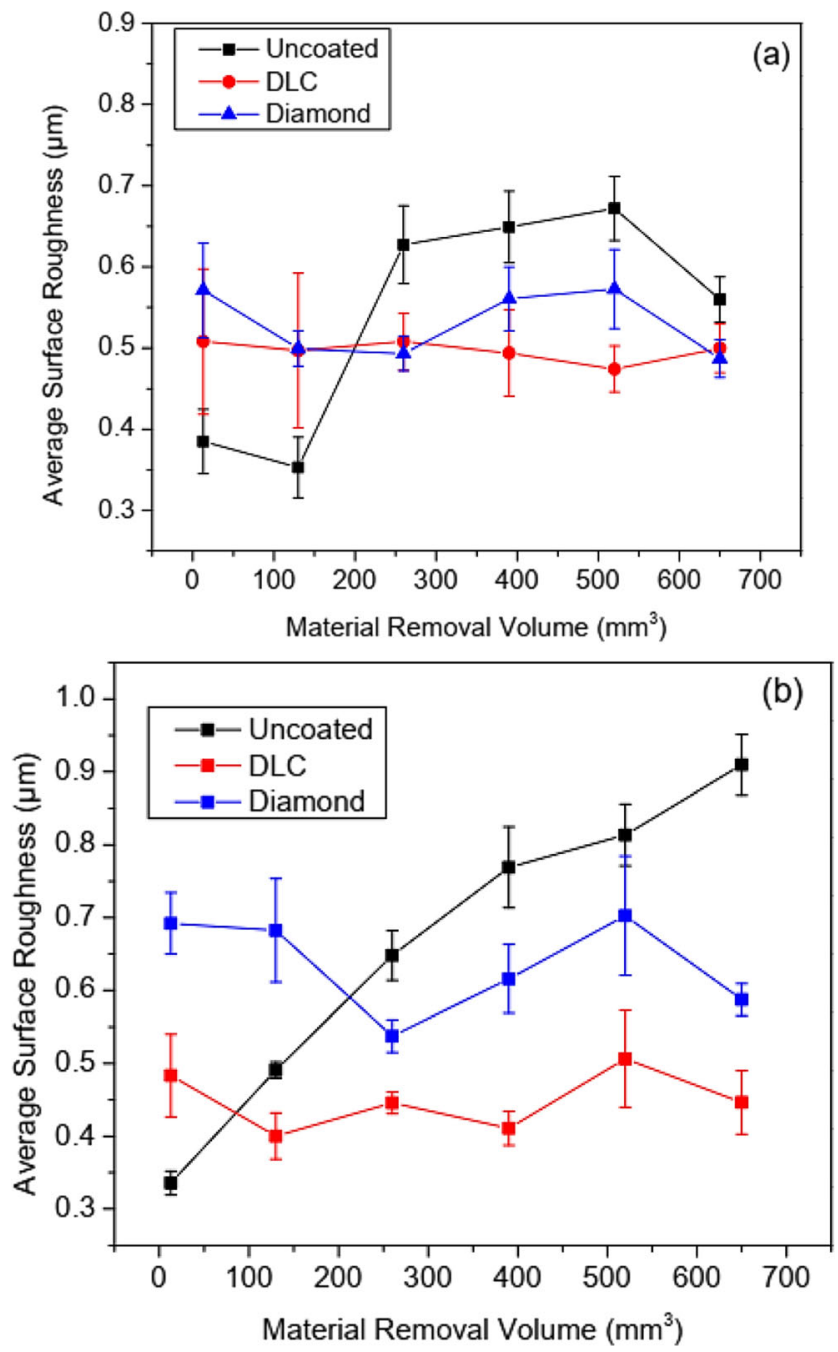

Fig. 8 Average surface roughness (Ra) variation as a function of material removal volume at various cutting speeds: a $62.8 \mathrm{~m} / \mathrm{min}$; b $188.4 \mathrm{~m} / \mathrm{min}$

used during the micro-cutting process. Additionally, the surface roughness' rise trend is mostly linear with the cutting volume in this cutting condition (uncoated tool at 188.4 $\mathrm{m} / \mathrm{min}$ ) (Fig. 8b). Simultaneously, some fall portions in Ra variation can be seen at the lower cutting speed, which can be explained by the material adhesion. Material adhered on uncoated tool surfaces at high cutting speed can be seen from the SEM images in Fig. 6a. These attached materials seem to blunt the micro-tools, and some loose portions of them can stick to the machined surfaces. All of these factors can result in low surface quality. The less chip adhesion on the uncoated tool at low cutting speed (Fig. 6b) may cause Ra trend fluctuations (Fig. 8a). However, cutting speed shows unobvious influences on the surface quality generated from using both DLC and diamond tools. The surface roughness has a noticeable rise in the diamond tool's case when increasing cutting speed from 62.8 to $188.4 \mathrm{~m} / \mathrm{min}$ (around 20\%). It is also related to the influence of chip adhesion as seen by the increase of diamond tool diameter at the end of the cutting process (Fig. 5b).

Figure 8 also reveals that using the DLC tool during the micro-milling process provided higher machined surface quality than others (uncoated and diamond tools), regardless of the cutting speed. Low cutting forces and tool wear rate from using DLC tools are two main factors that contribute to this phenomenon. The advantages of using DLC in higher surface finish than uncoated tools have been investigated by other researchers $[32,35,36]$. However, their applications in micro-milling of polymer nanocomposites have been minimal and lack of sufficient analysis of their performance. Therefore, DLC-coated tools seem to be more appropriate for micromachining graphene-reinforced epoxy nanocomposites compared to the diamond and uncoated tools, in particular, to improve surface finish. Figure 9 provides the quantitative data of the average surface roughness generated using different tools to consider cutting speed effect. It re-highlights the role of using DLC tools in reducing surface roughness compared to the diamond and uncoated tools, especially at high cutting speed $(188.4 \mathrm{~m} / \mathrm{min})$.

\subsection{Workpiece surface integrity}

Figure 10 shows SEM micro-graphs for the bottom surfaces of the machined slots. Intensive smearing (probably because of melting the matrix material) took place on specimens machined at higher cutting speeds $(188.4 \mathrm{~m} / \mathrm{min})$. Additionally, the SEM analysis revealed that internal defects such as air bubbles (internal cavities) exist that are likely to be formed during the nanocomposite samples' fabrication process. Feed marks are also observed in most machined surfaces that cut at low cutting speed $(62.8 \mathrm{~m} / \mathrm{min})$. Deterioration in workpiece

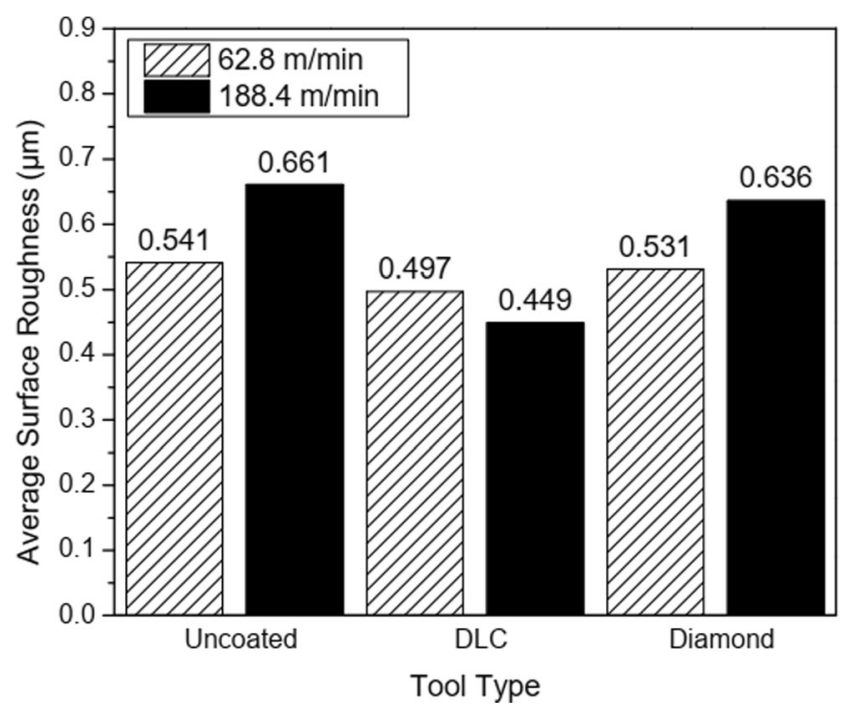

Fig. 9 Effect of cutting speed and tool coating type on average surface roughness (in $\mu \mathrm{m}$ ) at all cutting stages (from 10 to 500 slots) 
Uncoated
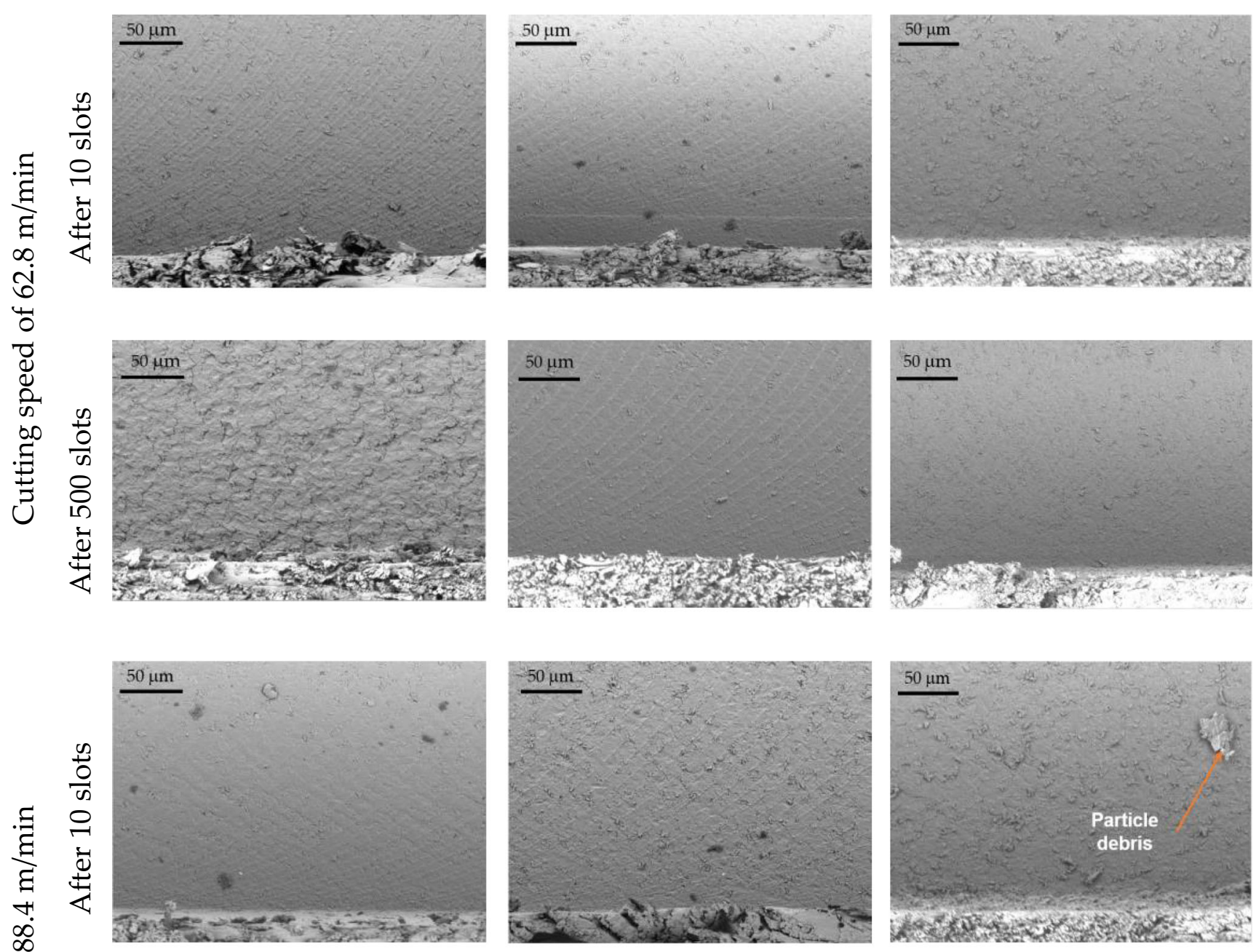

Diamond coating

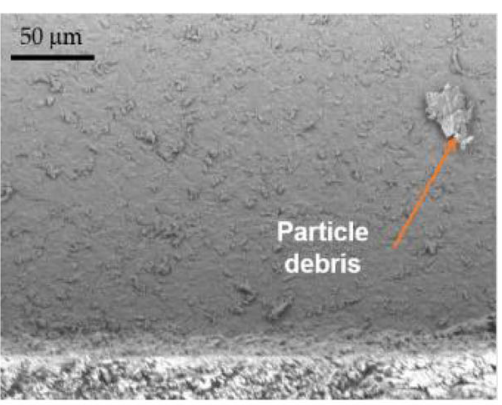

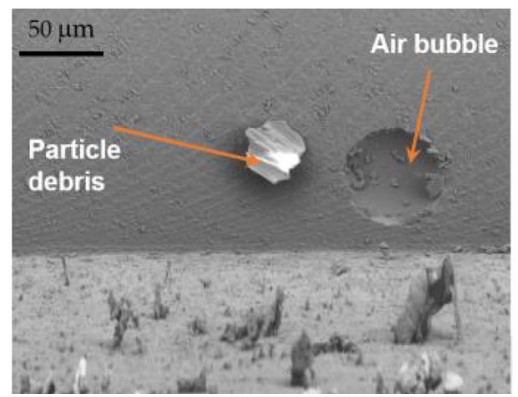

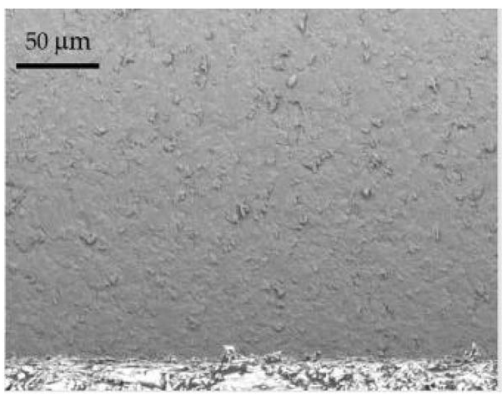

Fig. 10 SEM images of machined surface morphology at two cutting stages (after 10 and 500 slots) using different micro-end mills under various cutting speeds

surface quality with machining time is apparent for surfaces cut using the uncoated cutting tools compared with the DLC and diamond coated counterparts. This could be the result of severe cutting edge rounding observed only on the uncoated tools. It is also supported by the observed increase in surface roughness values versus material removal volume, as shown in Fig. 8.

\subsection{Slot width accuracy}

The presence of a $0.3 \%$ weight of graphene nanofiller in an epoxy resin/matrix is expected to improve the heat dissipation throughout the cutting process, enhancing the dimensional accuracy of the produced feature. Figure 11 shows the average slot width against cutting speed and cutting tool type. The 

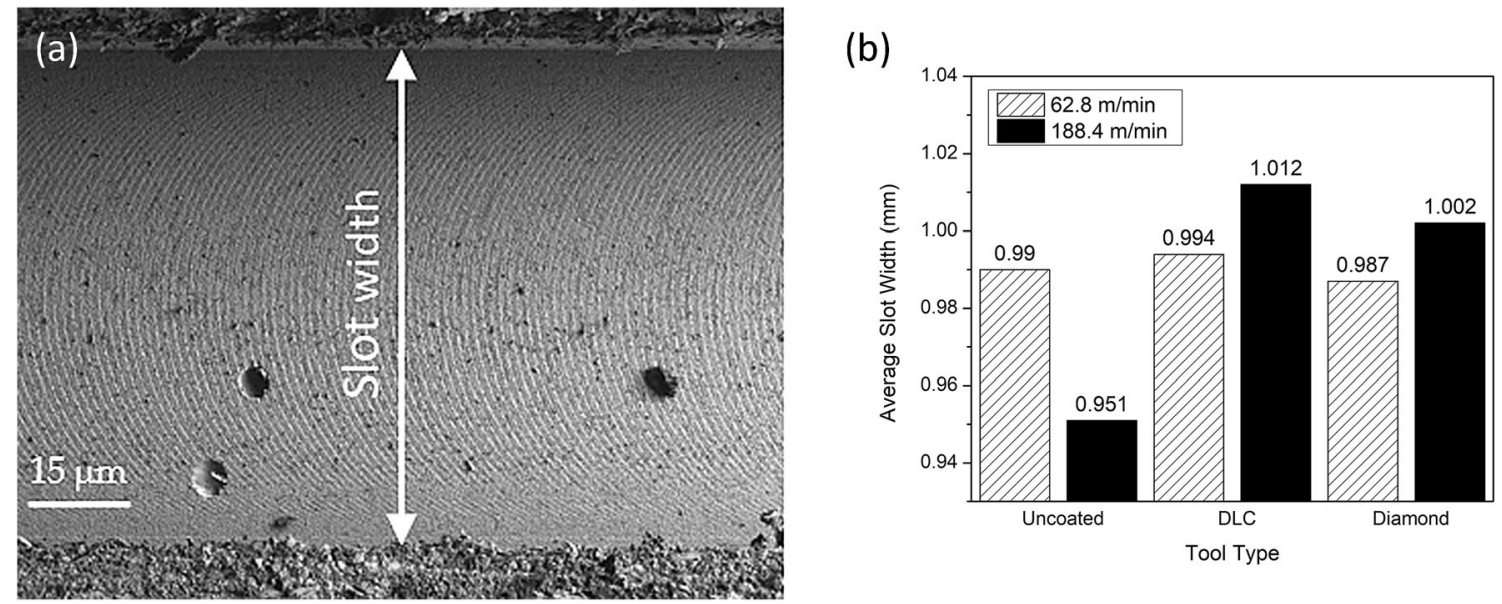

Fig. 11 a SEM image of a slot generated by DLC-coated tool at $62.8 \mathrm{~m} / \mathrm{min}$ after 500 slots. b Effect of cutting speed and tool coating type on average slot width (in $\mathrm{mm}$ ) at all cutting stages (from 10 to 500 slots)

results agree with the original diameter of the cutting tools, as shown in Fig. 5a. Unsurprisingly, marginal shrinkages in the machined slots are observed in all slots produced. This phenomenon explains slot width is always marginally smaller than the cutting tool's initial diameter for this test.

As shown in Fig. 11b, the tool coating leads to less width channel reduction. The operation of suitable coating with adequate adhesion supports tool for wear resistance and slows down the increase of edge roundness [34]. The remarkable width reduction could be assigned to tool wear enhancement of uncoated tool at $188.4 \mathrm{~m} / \mathrm{min}$ cutting speed.

\section{Conclusions}

In this study, micro-milling trials of $0.3 \mathrm{wt} \%$ graphenereinforced epoxy nanocomposites have been performed in dry cutting conditions. The corresponding tooling performances between three different tool types including tool wear, cutting force, dimensional accuracy surface roughness and surface integrity have been addressed and analysed. It has been observed that the micro-tools' wear behaviour depends upon the thermo-mechanical properties of the polymer nanocomposites, cutting speed and cutting force. The highest magnitudes cutting force, surface roughness and dimensional accuracy at high cutting speed reveal uncoated tools' poor performance compared with the other two coated tools. It has been further observed that the use of DLC micro-end mill in micro-machining of graphene-reinforced epoxy nanocomposites is recommended.

Author contributions Niusha Shakoori conceived and designed the experiment. Guoyu Fu and Long Jiang collected the data. Bao Le performed the analysis, interpreted the data and wrote and revised the paper. Jibran Khaliq, Islam Shyha and Dehong Huo revised and gave final approval of the version to be submitted, and all subsequent versions.
Funding The authors received the support from the Northumbria University.

Data and materials availability The datasets generated during and/or analysed during the current study are available from the corresponding author on reasonable request.

\section{Declarations}

Ethics approval This chapter does not contain any studies with human participants or animals performed by any of the authors. Authors acknowledge the work is original and all the relevant text from the literature has been properly cited.

Consent to participate Authors agree to the authorship order.

Consent for publication All authors have read and agreed to the published version of the manuscript.

Conflict of interest The authors declare no conflict of interest

Open Access This article is licensed under a Creative Commons Attribution 4.0 International License, which permits use, sharing, adaptation, distribution and reproduction in any medium or format, as long as you give appropriate credit to the original author(s) and the source, provide a link to the Creative Commons licence, and indicate if changes were made. The images or other third party material in this article are included in the article's Creative Commons licence, unless indicated otherwise in a credit line to the material. If material is not included in the article's Creative Commons licence and your intended use is not permitted by statutory regulation or exceeds the permitted use, you will need to obtain permission directly from the copyright holder. To view a copy of this licence, visit http://creativecommons.org/licenses/by/4.0/.

\section{References}

1. Shyha I, Fu GY, Huo DH, Le B, Inam F, Saharudin MS et al. (2018) Micro-machining of nano-polymer composites reinforced with graphene and nano-clay fillers. Key Eng Mater 197-205 
2. Balandin AA (2011) Thermal properties of graphene and nanostructured carbon materials. Nat Mater 10:569-581

3. Atif R, Shyha I, Inam F (2016) Mechanical, thermal, and electrical properties of graphene-epoxy nanocomposites-a review. Polymers 8:281

4. Papageorgiou DG, Kinloch IA, Young RJ (2017) Mechanical properties of graphene and graphene-based nanocomposites. Prog Mater Sci 90:75-127

5. Allahbakhsh A (2017) "High barrier graphene/polymer nanocomposite films," in Food Packaging, ed: Elsevier, pp. 699-737.

6. A. Manta, M. Gresil, and C. Soutis, "Graphene in aerospace composites: characterising thermal response," in AIP Conference Proceedings, 2018, p. 020001.

7. Yu B, Shi Y, Yuan B, Qiu S, Xing W, Hu W, Song L, Lo S, Hu Y (2015) Enhanced thermal and flame retardant properties of flameretardant-wrapped graphene/epoxy resin nanocomposites. J Mater Chem A 3:8034-8044

8. Zaman I, Manshoor B, Khalid A, Araby S (2014) From clay to graphene for polymer nanocomposites - a survey. J Polym Res 21:429

9. Elmarakbi A, Karagiannidis P, Ciappa A, Innocente F, Galise F, Martorana B, Bertocchi F, Cristiano F, Villaro Ábalos E, Gómez J (2019) 3-Phase hierarchical graphene-based epoxy nanocomposite laminates for automotive applications. J Mater Sci Technol 35: 2169-2177

10. Das TK, Prusty S (2013) Graphene-based polymer composites and their applications. Polym-Plast Technol Eng 52:319-331

11. Young RJ, Liu M (2016) The microstructure of a graphenereinforced tennis racquet. J Mater Sci 51:3861-3867

12. Young RJ, Kinloch IA, Gong L, Novoselov KS (2012) The mechanics of graphene nanocomposites: a review. Compos Sci Technol 72:1459-1476

13. Park YT, Qian Y, Chan C, Suh T, Nejhad MG, Macosko CW, Stein A (2015) Epoxy toughening with low graphene loading. Adv Funct Mater 25:575-585

14. Elmarakbi A and Azoti W (2018) "State of the art on graphene lightweighting nanocomposites for automotive applications," in Experimental Characterisation, Predictive Mechanical and Thermal Modeling of Nanostructures and their Polymer Composites, ed: Elsevier, pp. 1-23.

15. Kumar A, Sharma K, Dixit AR (2019) A review of the mechanical and thermal properties of graphene and its hybrid polymer nanocomposites for structural applications. J Mater Sci 54:5992-6026

16. Le B, Khaliq J, Huo D, Teng X, and Shyha I (2020) "A review on nanocomposites. Part 2: micromachining," J Manuf Sci Eng, 142.

17. Cardoso P, Davim JP (2012) A brief review on micromachining of materials. Rev Adv Mater Sci 30:98-102

18. Imbaby M, Jiang K (2010) Stainless steel-titania composite micro gear fabricated by soft moulding and dispersing technique. Microelectron Eng 87:1650-1654

19. Jiguet S, Judelewicz M, Mischler S, Bertch A, Renaud P (2006) Effect of filler behavior on nanocomposite SU8 photoresist for moving micro-parts. Microelectron Eng 83:1273-1276

20. Leo Kumar S, Jerald J, Kumanan S, Prabakaran R (2014) A review on current research aspects in tool-based micromachining processes. Mater Manuf Process 29:1291-1337
21. Lee I-y, Kannan E, Kim G-H (2009) Capacitance-voltage and current-voltage characteristics of graphite oxide thin films patterned by ultraviolet photolithography. Appl Phys Lett 95:343

22. Wojciechowski S, Matuszak M, Powałka B, Madajewski M, Maruda R, Królczyk G (2019) Prediction of cutting forces during micro end milling considering chip thickness accumulation. Int J Mach Tools Manuf 147:103466

23. Wu T, Cheng K, Rakowski R (2012) Investigation on tooling geometrical effects of micro tools and the associated micro milling performance. Proceedings of the Institution of Mechanical Engineers, Part B: J Eng Manuf 226:1442-1453

24. Arora I, Samuel J, and Koratkar N (2013) "Experimental investigation of the machinability of epoxy reinforced with graphene platelets," J Manuf Sci Eng, vol. 135

25. Teng X, Huo D, Shyha I, Chen W, Wong E (2018) An experimental study on tool wear behaviour in micro milling of nano $\mathrm{Mg} / \mathrm{Ti}$ metal matrix composites. Int J Adv Manuf Technol 96:2127-2140

26. Heaney PJ, Sumant AV, Torres CD, Carpick RW, Pfefferkorn FE (2008) Diamond coatings for micro end mills: enabling the dry machining of aluminum at the micro-scale. Diam Relat Mater 17: 223-233

27. Ucun İ, Aslantaș K, Gökçe B, Bedir F (2014) Effect of tool coating materials on surface roughness in micromachining of Inconel 718 super alloy. Proc Inst Mech Eng B J Eng Manuf 228:1550-1562

28. Samuel J, Dikshit A, DeVor RE, Kapoor SG, and Hsia KJ (2009) "Effect of carbon nanotube (CNT) loading on the thermomechanical properties and the machinability of CNTreinforced polymer composites," J Manuf Sci Eng: 131.

29. Wei J (2017) Graphene in epoxy system: dispersion, preparation and reinforcement effect. Northumbria University

30. Wei J, Atif R, Vo T, Inam F (2015) Graphene nanoplatelets in epoxy system: dispersion, reaggregation, and mechanical properties of nanocomposites. J Nanomater 2015

31. Niu Z, Jiao F, Cheng K (2018) An innovative investigation on chip formation mechanisms in micro-milling using natural diamond and tungsten carbide tools. J Manuf Process 31:382-394

32. Folea M, Roman A, and Lupulescu N.-B (2010) "An overview of DLC coatings on cutting tools performance," Academic Journal of Manufacturing Engineering, vol. 8.

33. Wu T, Cheng K (2013) Micro milling performance assessment of diamond-like carbon coatings on a micro-end mill. Proceedings of the Institution of Mechanical Engineers, Part J: Journal of Engineering Tribology 227:1038-1046

34. Aramcharoen A, Mativenga P, Yang S, Cooke K, Teer D (2008) Evaluation and selection of hard coatings for micro milling of hardened tool steel. Int J Mach Tools Manuf 48:1578-1584

35. Dai M, Zhou K, Yuan Z, Ding Q, Fu Z (2000) The cutting performance of diamond and DLC-coated cutting tools. Diam Relat Mater 9:1753-1757

36. Sousa VF, Silva FJ (2020) Recent advances on coated milling tool technology - a comprehensive review. Coatings 10:235

Publisher's note Springer Nature remains neutral with regard to jurisdictional claims in published maps and institutional affiliations. 